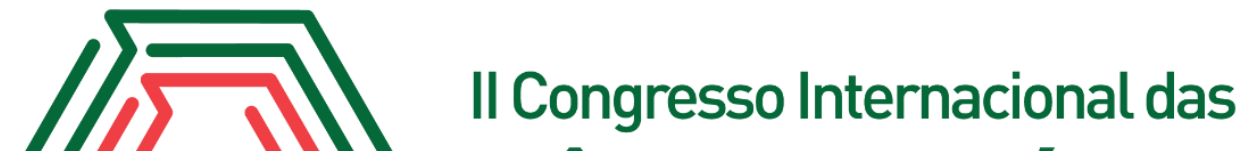 Ciências Agrárias COINTER - PDVAgro 2017
}

\section{AVALIAÇÃO DO VIGOR DE SEMENTES CRIOULAS DE FEIJÃO CAUPI DO SERTÃO DO CARIRI DO ESTADO DO CEARÁ}

\author{
Apresentação: Pôster
}

\begin{abstract}
Railany Brito de Lucena ${ }^{1}$; Patricya Lorena de Brito Rodrigues ${ }^{2}$; Bruna Marques Felipe ${ }^{3}$; Salenilza Pires de Almeida ${ }^{4}$; Edilza Maria Felipe Vásquez ${ }^{5}$.
\end{abstract}

\section{Introdução}

O feijão-caupi ou feijão-de-corda (Vigna unguiculata (L.) Walp.) é um componente de a dieta alimentar de povos em países subdesenvolvidos. Sua importância está no alto conteúdo de proteína nas sementes (AKANDE, 2007).

Os testes de vigor são utilizados para diferenciar os níveis de vigor entre as sementes, distinguindo-as também entre seus lotes. Estes testes são classificados em métodos diretos e métodos indiretos. Os diretos seriam os métodos que procuram simular as condições (às vezes adversas) que ocorrem no campo e os indiretos procuram avaliar atributos que indiretamente se relacionam com vigor (físicos, biológicos, fisiológicos) das sementes (CARVALHO \& NAKAGAWA, 2000).

O objetivo do trabalho foi avaliar a germinação e vigor de sementes crioulas de feijão-caupi do sertão do Cariri do estado do Ceará

\section{Fundamentação Teórica}

Por serem organismos vivos, as sementes realizam trocas de calor e umidade com o meio ambiente, atingindo o equilíbrio higroscópico (ELIAS et al., 2008). De acordo com Marcos Filho (2005) as sementes, naturalmente, reduzem a exigência hídrica do embrião, de modo a minimizar seu metabolismo para garantir a conservação do potencial fisiológico até a próxima semeadura;

\footnotetext{
${ }^{1}$ Agronomia, Universidade Federal do Cariri, railanybrito@hotmail.com

${ }^{2}$ Agronomia, Universidade Federal do Cariri, p.lorrenabrito@gmail.com

${ }^{3}$ Agronomia, Universidade Federal do Cariri, brunnamarques40@hotmail.com

${ }^{4}$ Agronomia, Universidade Federal do Cariri, as.anna.maria@gmail.com

${ }^{5}$ Prof. Dra. Em Fitotecnia, Universidade Federal do Cariri, edilza.felipe@ufca.edu.br
} 
recuperando suas funções biológicas quando reidratada.

O teste de germinação é o método aplicado e recomendado para determinação do potencial fisiológico das sementes, embora se reconheçam as suas limitações, por ser conduzido em condições ambientais ótimas (MARCOS FILHO, 2005).

O teste de vigor tem como objetivo básico identificar diferenças significativas na qualidade fisiológica entre lotes de sementes, bem como estimar a capacidade de emergência de plântulas no campo destes lotes, em condições desfavoráveis. (BINOTTI et al., 2008; BRAZ e ROSSETTO, 2009).

\section{Metodologia}

O experimento foi realizado no período de junho de 2017, no Laboratório de Biologia da Universidade Federal do Cariri - UFCA, situada no município do Crato-CE.

Foram utilizadas sementes crioulas de feijão caupi das variedades Manteiga, Azul e Verde as quais foram adquiridas junto a produtores da região. $\mathrm{O}$ experimento foi conduzido com quatro repetições de 25 sementes por tratamento. As sementes foram colocadas para germinar entre folhas de papel germitest, umedecido com água destilada na proporção de $2,5 \mathrm{x}$ o peso do papel seco, em seguida foi confeccionado os rolos de papel, os quais foram acondicionados em sacos plásticos e mantidos em germinador do tipo B.O.D. à temperatura de $30^{\circ} \mathrm{C}$. As variáveis analisadas foram porcentagem de germinação, plântulas anormais e sementes mortas de acordo com Brasil (2009).

Juntamente com o teste de germinação foram computadas diariamente e no mesmo horário as sementes germinadas para cálculo do Índice de Velocidade de Germinação (IVG), com emprego da fórmula proposta por Maguire (1962).

$$
I V G=E_{1} / N_{1}+E_{2} / N_{2}+\ldots+E_{m} / N_{n}
$$

Onde: $\mathrm{E}_{1}, \mathrm{E}_{2}, \ldots, \mathrm{E}_{\mathrm{m}}=\mathrm{n}^{\mathrm{o}}$ de plântulas emergidas, computadas na primeira, segunda, ..., última contagem $\mathrm{N}_{1}, \mathrm{~N}_{2}, \ldots, \mathrm{N}_{\mathrm{n}}=\mathrm{n}^{\mathrm{o}}$ de dias de semeadura à primeira, segunda, ..., última contagem

Para obtenção do Tempo Médio de Germinação (TM) e Sincronização da germinação (U) utilizou-se as fórmulas propostas por Labouriau (1983) como segue:

$$
\mathbf{T M}=(\Sigma \text { niti }) / \Sigma \text { ni }
$$

Onde: $\mathrm{TM}=$ tempo médio de germinação; ni= número de sementes germinadas por dia; ti= tempo de incubação (dias).

$$
\text { Fr }=\text { ni } / \Sigma n i
$$


onde: $F r=$ freqüência relativa de germinação; ni= número de sementes germinadas por dia; $\Sigma$ ni= número total de sementes germinadas.

\section{$\mathrm{U}=-\Sigma$ filogefi}

Foi usado o delineamento inteiramente casualizado, com três tratamentos e quatro repetições. Os dados foram submetidos à análise de variância pelo teste $\mathrm{F}$ e as médias dos tratamentos comparadas pelo teste de Tukey a 5\% de probabilidade.

\section{Resultados e Discussões}

Os resultados da análise de variância mostraram que houve efeito significativo entre os lotes sobre a porcentagem de plântulas normais e anormais (Gráfico 1 e 2, respectivamente). Para percentagem de germinação e plântulas anormais houve superioridade das variedades azul e verde. A variedade manteiga foi a de menor vigor. Para a porcentagem de semente morta/não germinada não houve diferença estatística entre as variedades.

Quando se observa o vigor pela velocidade de germinação através do índice de velocidade de germinação (IVG) e Tempo Médio de Germinação (TM), nos gráficos 3 e 4, respectivamente, percebe-se a superioridade das variedade manteiga e azul, as quais tiveram um maior valor de IVG e menor valor de TM. Esses resultados indicam que ambas as variedades apresentaram maior velocidade na germinação e conseqüentemente maior vigor em relação à cultivar verde.

Gráfico1. Percentagem de germinação de sementes de feijão caupi. (Tukey; 5\%). Fonte: Própria.

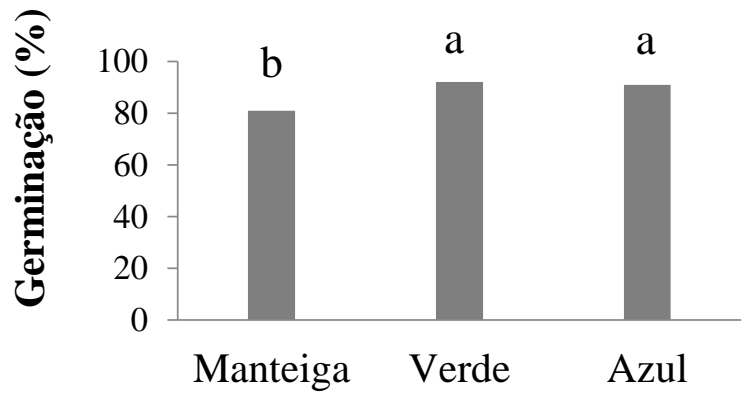

Cultivares
Gráfico2. Percentagem de plântulas anormais de sementes de feijão caupi. (Tukey; 5\%). Fonte: Própria.

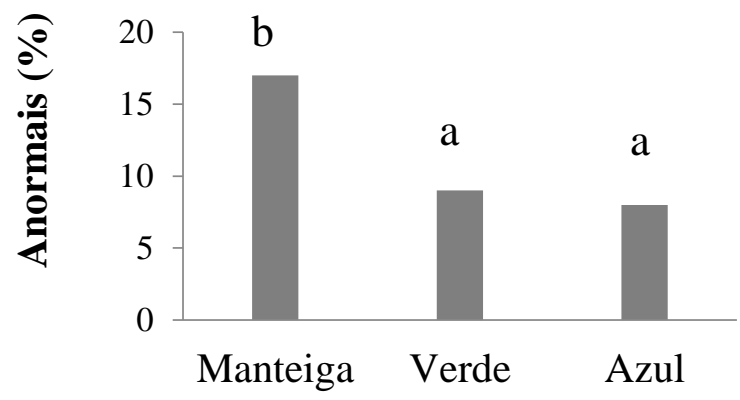

Cultivares 
Gráfico 3. Índice de velocidade de germinação (IVG) desementes de feijão caupi. (Tukey; 5\%). Fonte: Própria.

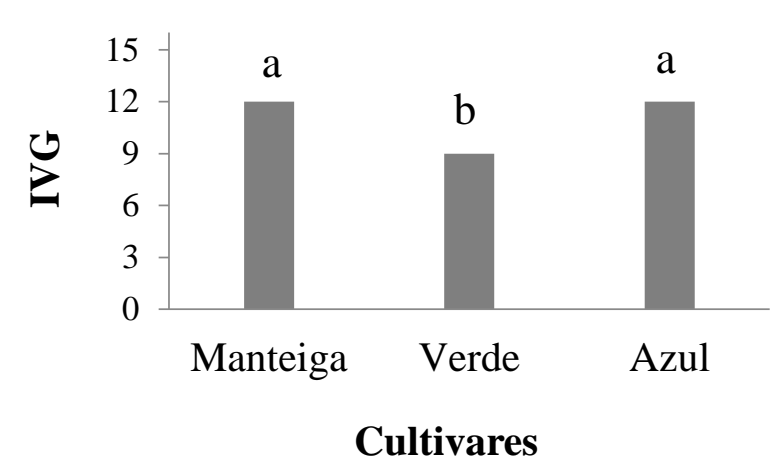

Gráfico 4.Tempo Médio de germinação (TM) de sementes de feijão caupi. (Tukey; 5\%). Fonte: Própria.

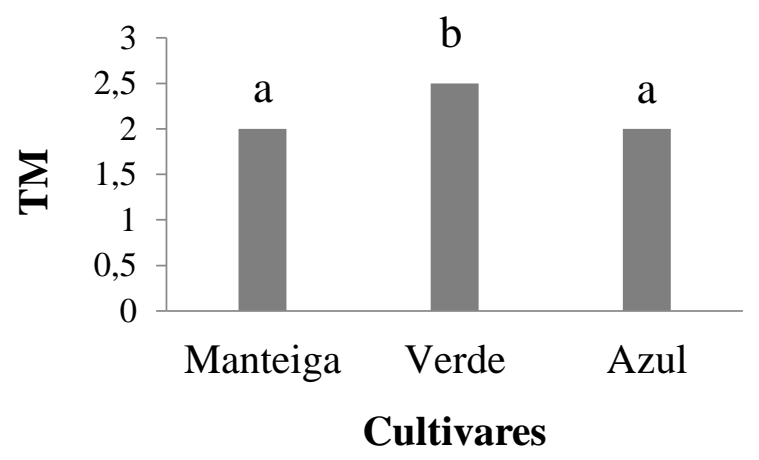

\section{Conclusão}

Conclui-se que a cultivar azul é superior quanto ao vigor em relação as cultivares verde e manteiga, sendo esta última a de menor vigor através dos testes realizados.

\section{Referências}

AKANDE, S.R. Genotype by environment interaction for cowpea seed yield and disease reactions in the forest and derived savanna agro-ecologies of south-west Nigeria. American-Eurasian Journal of Agricultural \& Environmental Science, v.2, p.163-168, 2007CARVALHO, N. M.; NAKAGAWA, J. Sementes: ciência, tecnologia e produção. 4. ed. Jaboticabal: Funep, 588 p.2007.

BRAZ, M. R. S. e ROSSETTO, C. A. V. Correlação entre testes para avaliação da qualidade de sementes de girassol e emergência das plântulas em campo. Ciência Rural, Santa Maria, v. 39, n.7, p. 2004-2009, Jul. 2009.

CARVALHO, N. M.; NAKAGAWA, J. Sementes: ciência, tecnologia e produção. 4. ed. Jaboticabal: Funep, 588 p.2000.

ELIAS, M. C.; de OLIVEIRA, M.; WALLY, A. P. S.; MORAS, S. R. de A.; ROCHA, J. da C. Desafios da pós-colheita na qualidade de arroz e feijão para indústria e consumo. in

MARCOS FILHO, J. Fisiologia de Sementes de plantas cultivadas. Piracicaba: Fealq, 2005. 495 p. 